\title{
Senso crítico, analítico e científico de estudantes do 60 ano do ensino fundamental numa sequência didática sobre a pegada ecológica do lixo
}

Ronualdo Marques

ronualdo.marques@gmail.com 0000-0001-6681-9914

Universidade Tecnológica Federal do Paraná, Curitiba, Paraná, Brasil.

Claudia Regina Xavier cxavierutfpr@gmail.com 0000-0001-6346-648X Universidade Tecnológica Federal do Paraná, Curitiba, Paraná, Brasil.

\section{RESUMO}

A Educação Ambiental como temática transversal no currículo do Ensino de Ciências possibilita reflexões e discussões para que este saber contribua com uma nova postura com ações em sua relação com o meio ambiente. Essa pesquisa teve como objetivo analisar as evidências do desenvolvimento do senso crítico, analítico e cientifico de estudantes com a aplicação de uma Sequência Didática sobre a Pegada Ecológica do Lixo. Pôde-se concluir que a inserção da Educação Ambiental no currículo escolar de forma contextualizada pode ressignificar o modo de ensino e romper com práticas isoladas e pontuais e com a Educação mecanicista e conservadora, visto que o desenvolvimento de ações integradas e participativas potencializa as discussões que emergem das relações entre o homem, sociedade e natureza. Além disso, o processo de sensibilização dos estudantes quantos aos problemas relacionados á temática lixo contribuem para que se tornem cidadãos críticos, analíticos e alfabetizados cientificamente, sendo ativos na preservação do ambiente.
\end{abstract}

PALAVRAS-CHAVE: Pegada ecológica do lixo. Educação ambiental. Ensino de ciências. 


\title{
INTRODUÇÃO
}

Ensinar ciências é propiciar aos alunos situações de aprendizagem nas quais eles poderão construir conhecimentos sobre diferentes fenômenos naturais (GUIMARÃES, 2009). A escola contemporânea almeja oferecer uma educação comprometida com os múltiplos aspectos relacionados às atividades produzidas pela ação humana, "os quais envolvem não só os problemas socioeconômicos, mas também os fatores éticos e afetivos, bem como os anseios existenciais quanto ao sentido da vida" (FREITAS et al., 2000).

Ao situarmos diante de tais problemáticas têm-se a possibilidade de se estabelecer uma ligação com os temas ambientais no processo de ensino e aprendizagem no currículo do Ensino de Ciências visto que possui inúmeras unidades temáticas no currículo que contribuem com a promoção da Educação Ambiental. Entende-se que o Ensino das Ciências Naturais deve permitir ao aluno a compreensão da ciência como um processo humano e desenvolver uma postura crítica e reflexiva sobre os fenômenos naturais e a forma como o ser humano atua no ambiente (BRASIL, 1999). Mas, além disso, hoje se faz necessário que os alunos tenham uma compreensão dos conhecimentos científicos e tecnológicos, que lhes permitam atuar de maneira consciente sobre o mundo.

\begin{abstract}
Juntamente com a meta de proporcionar o conhecimento científico e tecnológico à imensa maioria da população escolarizada, deve-se ressaltar que o trabalho docente precisa ser direcionado para sua apropriação crítica pelos alunos, de modo que efetivamente se incorpore no universo das representações sociais e se constitua como cultura (DELIZOICOV, 2009, p. 34).
\end{abstract}

A formação de cidadãos críticos é uma necessidade social e uma das responsabilidades da educação, sendo o desenvolvimento do senso crítico uma das orientações presente nos Parâmetros Curriculares Nacionais (PCN). No PCN, a capacidade de argumentação é entendida como relevante para o adequado exercício da cidadania, possibilitando ao aluno "posicionar-se de maneira crítica, responsável e construtiva nas diferentes situações sociais [...]" (BRASIL, 1998, p. 7).

Sauvé (2005, p. 01) afirma que na origem dos atuais problemas socioambientais tais como, os relacionados ao consumismo desenfreado ocasionando a geração de resíduos, poluição, degradação do solo, contaminação da água etc, existe uma lacuna fundamental entre o ser humano e a natureza, que é importante eliminar. "É preciso reconstruir nosso sentimento de pertencer à natureza" (MARQUES; XAVIER, 2018a, p. 134). Sendo assim, Marques e Xavier reiteram que dentro de uma visão crítica e transformadora, os temas ambientais não devem ser tratados desvinculados da realidade dos estudantes.

Nesse cenário, Marques e Xavier (2018) asseveram que,

a inserção da Educação Ambiental (EA) no currículo do Ensino de Ciências pode ser uma como possibilidade para a formação e construção desse novo pensar, por tratar-se no sentido da educação como um processo educativo que se destina à formação de valores e atitudes necessários a uma nova postura por meio de ações e atitudes frente às questões ambientais, por meio de um processo educativo transformador e emancipatório (MARQUES; XAVIER, 2018, p. 123).

Para Loureiro, 
A ação emancipatória é o meio reflexivo, crítico e autocrítico contínuo, pelo qual podemos romper com a barbárie do padrão vigente de sociedade e de civilização, em um processo que parte do contexto societário em que nos movimentamos do "lugar" ocupado pelo sujeito, estabelecendo experiências formativas em que a reflexão problematizadora da totalidade, apoiada numa ação consciente e política, propiciam a construção de sua dinâmica (LOUREIRO 2006, p. 32).

A Educação Ambiental como temática transversal no currículo do Ensino do Ciências promove "um processo intelectual ativo enquanto aprendizado social, baseado no diálogo e interação em constante processo de recriação e reinterpretação de informações, conceitos e significados, que se originam do aprendizado em sala de aula ou da experiência pessoal do aluno" (MARQUES e XAVIER, 2018a, p. 134). Assim, podemos considerar a Ciência como "uma linguagem para facilitar nossa leitura do mundo natural" (CHASSOT, 1993, p. 37), tê-la como meio de descrição do mundo natural ajuda a entendermos a nós mesmos e as relações intrínsecas com ambiente que nos circunda, tendo que ao abordar temáticas relacionadas ao Meio Ambiente possam-se articular essas de modo a ser ressignificadas.

Entretanto, ao compreendermos o conhecimento como meio para a sensibilização e conscientização dos indivíduos deverá se mostrar através da articulação com o conhecimento "a capacidade de optarmos pelo compromisso com o outro, com a sua subjetividade e, antes de tudo, com a sua maneira de ser no mundo e estabelecer nele as suas mediações vivenciais que o realizam como ser social e como ser da cultura" (MARQUES e XAVIER, 2018a, p. 135).

Loureiro ao trazer o sentido da educação para o rompimento do senso comum afirma que,

Educar é negar o senso comum, é entender que não podemos pensar pelo outro, para o outro e sem o outro. A Educação é feita com o outro que também é sujeito, que tem sua identidade e individualidade a serem respeitadas no processo de questionamento, dos comportamentos e da realidade (LOUREIRO, 2006, p. 28).

Os temas ambientais numa abordagem reducionista sem sua sistematização e problematização a partir dos debates "dos conteúdos de Ciências Naturais não garantem as reflexões necessárias á compreensão dos diferentes modos da relação homem, sociedade e natureza" (AMARAL, 2001) pois, estes constituem questões sociais relevantes para as discussões no contexto escolar destacando os inúmeros problemas urgentes; todavia é comum que os discentes em quaisquer níveis educacionais apresentem dificuldades para a aprendizagem e as discussões sobre a EA, dada à complexidade das questões socioambientais. Essa é considerada um componente urgente e essencial no Ensino Fundamental no 60 ano, onde abrange uma importante quantidade de temas ambientais que contribui para a formação de cidadãos e para atuação na realidade socioambiental. Desta maneira, esse estudo teve por objetivo analisar as evidências do desenvolvimento do senso crítico, analítico e cientifico de estudantes a partir da aplicação de uma Sequência Didática sobre a Pegada Ecológica do Lixo. Com essa aspiração inicial a ser aprofundada e analisada a luz da literatura temos a seguinte indagação "Como ocorre á formação do senso crítico, analítico e cientifico dos alunos do 60 ano do Ensino Fundamental através da Educação Ambiental?". 


\section{O DESENVOLVIMENTO DO SENSO CRÍTICO, ANALÍTICO E CIENTÍFICO}

\subsection{Senso crítico}

Ao pensar na educação da atualidade diante dos problemas sociais e ambientais, o senso crítico é posto como um dos principais elementos que se busca no processo de ensino e aprendizagem na atualidade, pois o senso crítico é voltado para a formação de cidadãos participativos e atuantes sobre a sua realidade. Marques e Xavier afirmam que "um indivíduo que possui a capacidade de analisar e discutir problemas a partir de uma investigação racional, sem aceitar, de forma automática, suas próprias opiniões ou opiniões alheias, é um indivíduo dotado de senso crítico" (MARQUES e XAVIER, 2018a, p. 137).

Segundo Carraher (2011) uma pessoa com senso crítico se constitui das seguintes características:

a) Atitude de constante curiosidade intelectual e questionamento;

b) Habilidade de pensar logicamente;

c) Habilidade de perceber a estrutura de argumentos em linguagem natural;

d) Perspicácia, isto é, a tendência de perceber além do que é dito explicitamente, descobrindo as ideias subentendidas e subjacentes;

e) Consciência pragmática, reconhecimento e apreciação dos usos práticos da linguagem como meio de alcançar objetivos e influir sobre outros;

f) Distinção entre questões de fato, de valor e questões conceituais;

g) Habilidade de penetrar até ao cerne de um debate, avaliando a coerência de posições e levantando questões que possam esclarecer à problemática (CARRAHER, 2011).

A partir dessas características Marques e Xavier (2018a) afirmam que a curiosidade intelectual envolve um estilo questionador de abordar problemas na vida diária, social, profissional etc. O sujeito crítico questiona e analisa as coisas não porque alguém exige que ele o faça, mas porque no fundo, ele tem um desejo de compreender, um:

interesse em descobrir por si mesmo, as respostas a interrogações nascidas do contato com pessoas e coisas. A curiosidade assume caráter definidamente intelectual quando e somente quando um alvo distante controla uma sequência de investigações e observações, ligando-as uma a outra como meios para um fim (DEWEY, 1959, p. 46).

Segundo Marques e Xavier (2018a) a curiosidade intelectual "depende de um investimento do indivíduo para o questionamento dos fenômenos de um problema analisado. Primeiro, o sujeito crítico precisa ter uma tolerância e até predileção por estados cognitivos de conflito, em que o problema ainda não é totalmente compreendido" (MARQUES e XAVIER, 2018a, p. 138). Dessa forma, se ele ficar aflito quando não sabe a "resposta correta", essa ansiedade pode impedir a exploração mais completa de um problema (CARRAHER, 2011).

Nesse ínterim Marques e Xavier (2018a) afirmam que, é simplesmente uma questão do caráter do indivíduo. O sujeito menos exigente consigo mesmo tende a limitar as interpretações às suas próprias perspectivas ou àquelas que satisfaçam as exigências mínimas. Honestidade intelectual significa estar disposto a reformular posições diante de novas informações, a questionar suas próprias opiniões e a questionar posições que constituem "modas intelectuais". Uma atitude de curiosidade intelectual 
implica em adotar perspectivas múltiplas, para examinar as questões sob várias óticas (MARQUES e XAVIER, 2018a, p. 138).

Carraher (2011) afirma que o sujeito crítico não é um "polivalente" que entra em qualquer campo para elucidar suas questões fundamentais. Cada campo tem suas próprias premissas, o seu próprio "bom senso", suas próprias perspectivas. Assim,

\footnotetext{
o exercício do senso crítico num determinado campo exige conhecimento íntimo das questões conceituais, das tradições, dos conflitos atuais, dos paradoxos e dos estilos comunicativos, enfim, um conhecimento das práticas e da rede de significados naquele campo (CARRAHER, 2011, p. 21).
}

Dessa forma, o conhecimento crítico permite ao indivíduo, como menciona Badaró (2005, p. 34), "um processo de apropriação mental com relação ao mundo no qual faz parte, na tentativa de elaborar explicações e reflexões distintas dos diferentes fatos e fenômenos que o circundam." O conceito de criticidade está desta forma, associado ao ato de voltar-se para si mesmo na busca de reflexões que levem o indivíduo a compreender melhor o que faz, vivencia e sente.

Carraher (2011) enfatiza que através da apropriação do conhecimento tende a "incentivar o desenvolvimento de certas atitudes e procedimentos que não são habituais na vida cotidiana". Essas atitudes devem estar ligadas a outras como compreender conceitos e teorias cientificas, adquirir competências cognitivas, associadas à prática de ciência, bem como fomentar uma atitude cientifica de olhar o mundo e, por fim, desenvolver competências para usar o conhecimento científico na resolução de problemas (BADARÓ, 2005, p. 108).

Ao introduzir os sujeitos nas discussões e apropriação do conhecimento das Ciências o sujeito crítico deve buscar a "clareza e o rigor no seu pensamento, a coragem de adotar uma perspectiva ampla dos problemas que ele está estudando", e a outra, "integrar suas observações em sistemas explicativos que visam esclarecer questões amplas e que têm relevância para todas as outras pessoas" (CARRAHER, 2011, p. 16).

Marques e Xavier (2018a) asseveram que o sujeito crítico,

precisa manter sempre uma perspectiva ampla dos problemas que ela estuda, precisa estabelecer associações, usar sua intuição, formular ideias novas, ver semelhanças entre eventos e áreas de conhecimento aparentemente não relacionadas, explorar implicações, sugerir novas investigações, olhar os fenômenos de novas maneiras - em uma palavra: criar. Por outro lado, precisa desenvolver rigor na comunicação de suas ideias e em seu próprio raciocínio. Precisa desenvolver a capacidade de refletir sobre suas próprias ideias e observações, controlando o impulso de suas ideias e de aceitar sua intuição ou primeira avaliação dos fenômenos de modo pouco crítico, precisa analisar suas ideias e as de outras pessoas para poder melhorar o seu conhecimento (MARQUES e XAVIER, 2018a, p. 140).

A educação, por sua vez, só favorecerá o pensamento crítico quando desempenhar um papel significante nos processos sociopolíticos, pois está relacionada ao desenvolvimento da autoconsciência crítica. Essa crítica implicaria o rompimento com o discurso antigo, seja no âmbito teórico ou prático, para recriar um novo processo cultural. A perspectiva baseada na criticidade deve ser capaz de neutralizar a teoria antiga, mostrando sua incoerência (BATISTA, 2009, p. 27). 


\subsection{Senso Analítico}

Marques e Xavier (2019b, p. 5) afirmam que "o senso analítico está ligado à capacidade de analisar e ver o detalhe e encontrar soluções seja com base em números ou em percepções. A capacidade de análise está atrelada a nossa capacidade de enxergar o mundo com outros olhos". Nesse paralelo, é possível afirmar que vivemos em dois mundos, um das ideias e outro da realidade. Nossa mente é capaz de lidar com estas duas realidades e uma modifica radicalmente a outra. Esta relação que desenvolve entre as ideias e a realidade sobrevém das reflexões de fatos concretos, argumentações e análise, o que possibilita o desenvolvimento do senso analítico.

Marques (2018b) e Marques e Xavier (2019b) expõem elementos que contribuem para que uma pessoa desenvolva o senso analítico, ou seja, alguém capaz de conectar as ideias à realidade; são eles:

a) entender como a nossa mente funciona e quebrar o processo automático;

b) entender a organização dos dados;

c) entender o que é informação e como desenvolver a capacidade de análise;

d) estruturar a informação para facilitar a tomada de decisão;

e) incorporar a cultura da tomada de decisão a partir de dados e fatos concretos (MARQUES, 2018b; MARQUES; XAVIER, 2019, p. 5).

Zoller (1993 apud Mortimer e Santos, 2001, p. 99) apresenta um detalhamento sobre passos para o processo da estruturação da informação, solução de problemas e a tomada de decisão que está diretamente relacionada ao desenvolvimento do senso analítico. Segundo eles, os currículos deveriam ser estruturados de forma a propiciar condições para que os alunos desenvolvam os passos da tomada de decisão, os quais consistem em:

1. Reconhecimento da existência de um problema;

2. Compreensão da essência factual do conhecimento e conceitos envolvidos;

3. Apreciação do significado e sentido das soluções alternativas;

4. Processamento para solução do problema: a) Seleção de dados e informações relevantes; b) Análise dos dados pela sua racionalidade, confiabilidade e validade; c) Avaliação da dependência das fontes de informações usada e seus graus de preconceito; d) Planejamento de estratégias apropriadas para mais adiante negociar com os problemas; 5. Esclarecimento dos valores de cada um e estabelecimento de um julgamento de valor;

6. Processamento para a tomada de decisão: a) Escolhas racionais entre alternativas disponíveis ou geração de novas opções; b) Tomada de decisão;

7. Ação de acordo com a decisão tomada;

8. Tomada de responsabilidade (ZOLLER, 1993, p. 97).

Assim, a tomada de decisão como elemento para a formação do senso analítico, também é encontrada na literatura como uma das características da capacidade analítica, que é definida por Amaral (2006) como a capacidade de avaliar e interpretar sistematicamente os dados, a fim de identificar fatos relevantes, insights e relacionamentos-chave, para o estabelecimento de conclusões úteis à tomada de decisão, como mostrado no Quadro 1 a seguir: 


\begin{tabular}{|c|c|c|}
\hline Conhecimento & Habilidades & Atitude \\
\hline $\begin{array}{c}\text { - Organização de } \\
\text { informações }\end{array}$ & $\begin{array}{c}\text { - Aprender com as } \\
\text { experiências; } \\
\text { - Capacidade de síntese; } \\
\text { - Discernimento; } \\
\text { - Extrair dados relevantes; } \\
\text { - Gerar explicações } \\
\text { consistentes dos fatos; } \\
\text { - Gerar recomendações de } \\
\text { acordo com a análise; } \\
\text { - Interpretação de dados- } \\
\text { Intuição } \\
\text { - Julgamento } \\
\text {-Lidar com ambiguidades, } \\
\text { conflitos e dados } \\
\text { incompletos; } \\
\text { - Organizar informações; } \\
\text { - Pensamento analítico; } \\
\text { - Perspicácia; } \\
\text { - Raciocínio estratégico; } \\
\text { - Raciocínio lógico; } \\
\text { - Resolução de problemas; } \\
\text { - Visão de futuro; } \\
\text { - Visão global. }\end{array}$ & $\begin{array}{c}\text { - Agilidade; } \\
\text { - Confiabilidade; } \\
\text { - Estar constantemente } \\
\text { atento às informações; } \\
\text { - Criatividade } \\
\text { - Curiosidade } \\
\text { - Discrição } \\
\text { - Meticulosidade } \\
\text { - Observação } \\
\text { - Organização } \\
\text { - Percepção } \\
\text { - Segurança; } \\
\text { - Seriedade; }\end{array}$ \\
\hline
\end{tabular}

Fonte: Adaptado de Amaral (2006).

Partindo dos estudos de Amaral (2006) o senso analítico está diretamente ligado à capacidade analítica e é uma característica que diz respeito às habilidades de analisar dados, nem sempre diretamente relacionados entre si, e a partir desta análise produzir informação de valor ou conhecimento. Também diz respeito à capacidade de receber informações de várias fontes e organizar esta informação de forma racional. Como apresentados no Quadro 1 sobre a capacidade analítica, baseado no conhecimento, habilidades e atitudes.

\subsection{Senso científico}

O senso científico e seu desenvolvimento neste trabalho serão abordados a partir da Alfabetização Científica na construção de conceitos. Este é extremamente relevante na presente pesquisa, uma vez que constitui um meio eficaz que favorece a ampliação dos conhecimentos, bem como a observação e a compreensão do desenvolvimento científico.

Ressalta-se que a intenção da Alfabetização Científica não é doutrinar, mas "[...] objetiva que os assuntos científicos sejam cuidadosamente apresentados, discutidos, compreendendo seus significados e aplicados para o entendimento do mundo" (LORENZETTI e DELIZOICOV, 2001, p. 05).

Sasseron e Carvalho (2008) em seus estudos procuraram por indicadores de Alfabetização Científica no processo de ensino e aprendizagem da área do Ensino de Ciências na qual apresentou eixos estruturantes com ideias e habilidades a 
serem desenvolvidas com o intuito de que a Alfabetização Científica pudesse se revelar no processo de ensino e aprendizagem a partir da sistematização do conhecimento científico. Estes três pontos denominados pelas autoras de Eixos Estruturantes da Alfabetização Científica, são:

\begin{abstract}
(a) a compreensão básica de termos e conceitos científicos, retratando a importância de que os conteúdos curriculares próprios das Ciências sejam debatidos na perspectiva de possibilitar o entendimento conceitual; (b) a compreensão da natureza da ciência e dos fatores que influenciam sua prática, deflagrando a importância de que o fazer científico também ocupa espaço nas aulas de mais variados modos, desde as próprias estratégias didáticas adotadas, privilegiando a investigação em aula, passando pela apresentação e pela discussão de episódios da história das ciências que ilustrem as diferentes influências presentes no momento de proposição de um novo conhecimento; e (c) o entendimento das relações entre Ciência, tecnologia, sociedade e ambiente, permitindo uma visão mais completa e atualizada da Ciência, vislumbrando relações que impactam a produção de conhecimento e são por ela impactadas, desvelando, uma vez mais, a complexidade existente nas relações que envolvem o homem e a natureza (SASSERON; CARVALHO, 2008, p. 335).
\end{abstract}

Marques e Xavier (2018) destacam que mesmo que "os três eixos estruturantes apresentados anteriormente possam não se fazer presentes em todas as aulas, é necessário que eles sejam equitativamente considerados ao longo do desenvolvimento de um tema". Destes eixos se estabeleceram os Indicadores de Alfabetização Científica propostos por Sasseron e Carvalho (2008), em que consideraram as habilidades utilizadas pelos cientistas durante suas investigações, mostrando o encaminhamento de ações que levam à resolução de um problema de tema científico, e que servem como parâmetros para identificar que a Alfabetização Científica está em processo.

A seguir no Quadro 2 são apresentados e descritos alguns Indicadores da Alfabetização Científica listadas na obra de SASSERON e CARVALHO, (2008).

Quadro 2 - Indicadores de Alfabetização Científica

\begin{tabular}{|c|c|c|}
\hline $\begin{array}{c}\text { Indicadores da } \\
\text { Alfabetização Científica }\end{array}$ & Tipo & Descrição \\
\hline \multirow{3}{*}{$\begin{array}{l}\text { Indicadores para trabalhar } \\
\text { com os dados de uma } \\
\text { investigação }\end{array}$} & Seriação de informações & $\begin{array}{c}\text { Indicador que não } \\
\text { necessariamente prevê } \\
\text { uma ordem a ser } \\
\text { estabelecida, mas pode ser } \\
\text { um rol de dados, uma lista } \\
\text { de dados trabalhados. }\end{array}$ \\
\hline & $\begin{array}{l}\text { Organização de } \\
\text { Informações }\end{array}$ & $\begin{array}{l}\text { Ocorre nos momentos em } \\
\text { que se discute sobre o } \\
\text { modo como um trabalho } \\
\text { foi realizado. }\end{array}$ \\
\hline & $\begin{array}{l}\text { Classificação de } \\
\text { informações }\end{array}$ & $\begin{array}{l}\text { Ocorre quando se busca } \\
\text { conferir hierarquia às } \\
\text { informações obtidas. }\end{array}$ \\
\hline $\begin{array}{l}\text { Indicadores para } \\
\text { estruturação do } \\
\text { pensamento }\end{array}$ & Raciocínio Lógico & $\begin{array}{l}\text { Compreende o modo como } \\
\text { às ideias são desenvolvidas } \\
\text { e apresentadas e está } \\
\text { diretamente relacionada à }\end{array}$ \\
\hline
\end{tabular}




\begin{tabular}{|c|c|c|}
\hline & & $\begin{array}{c}\text { forma como o pensamento } \\
\text { é exposto. }\end{array}$ \\
\hline & Raciocínio proporcional & $\begin{array}{l}\text { Mostra como se estrutura } \\
\text { o pensamento, e refere-se } \\
\text { também à maneira como } \\
\text { variáveis têm relações } \\
\text { entre si, ilustrando a } \\
\text { interdependência que } \\
\text { pode existir entre elas. }\end{array}$ \\
\hline \multirow{5}{*}{$\begin{array}{c}\text { Indicadores para } \\
\text { entendimento da situação } \\
\text { analisada }\end{array}$} & $\begin{array}{l}\text { Levantamento de } \\
\text { Hipóteses }\end{array}$ & $\begin{array}{l}\text { Aponta instantes em que } \\
\text { são alçadas suposições } \\
\text { acerca de certo tema (pode } \\
\text { surgir como uma afirmação } \\
\text { de uma pergunta). }\end{array}$ \\
\hline & Teste de hipóteses & $\begin{array}{c}\text { Colocar à prova as } \\
\text { suposições anteriormente } \\
\text { levantadas (pode ocorrer } \\
\text { tanto diante da } \\
\text { manipulação direta de } \\
\text { objetos quanto no nível das } \\
\text { ideias). }\end{array}$ \\
\hline & Justificativa & $\begin{array}{l}\text { Quando em uma afirmação } \\
\text { qualquer proferida lança } \\
\text { mão de uma garantia para } \\
\text { o que é proposto. }\end{array}$ \\
\hline & Previsão & $\begin{array}{l}\text { É explicitado quando se } \\
\text { afirma uma ação e/ou } \\
\text { fenômeno que sucede } \\
\text { associado a certos } \\
\text { acontecimentos. }\end{array}$ \\
\hline & Explicação & $\begin{array}{l}\text { Quando se busca relacionar } \\
\text { informações e hipóteses já } \\
\text { levantadas. (Estão } \\
\text { relacionadas à justificativa } \\
\text { para o problema). }\end{array}$ \\
\hline
\end{tabular}

Fonte: Sasseron e Carvalho (2008).

Sasseron e Carvalho (2008) considera-se que a aquisição do conhecimento é fundamental para a resolução de problemas do dia a dia. No entanto, ao elencar os Indicadores de Alfabetização Científica inferem que a manifestação de um indicador não inibe a presença de outros.

Sasseron e Carvalho (2008) apresentam situações didáticas que oferecem aos alunos a chance de trabalhar com conteúdos científicos de maneira diferenciada e ao professor a chance de observar e delinear de maneira mais clara os resultados da aprendizagem de seus alunos. Para tanto, atentaram-se aos indícios demonstrados pela participação dos alunos em sala e que denotavam uma ou várias situações de aprendizagem em Ciências (MARQUES e XAVIER, 2019a, p 2598). A esses indícios de aprendizagem Sasseron e Carvalho destacam que os indicadores anteriormente descritos no Quadro 2, têm, 
resolução, discussão e divulgação de problemas em quaisquer das Ciências quando se dá a busca por relações entre o que se vê do problema investigado e as construções mentais que levem ao entendimento dele. Assim sendo, reforçamos nossa ideia de que o ensino de ciências deva ocorrer por meio de atividades abertas e investigativas nas quais os alunos desempenhem o papel de pesquisadores (SASSERON; CARVALHO, 2008, p. 338).

Del-Corso (2014) propôs indicadores de Alfabetização Científica tendo como base os Indicadores de Alfabetização Científica de Sasseron e Carvalho (2008), resultando em novos indicadores como apresentado no Quadro 3 que complementam e integram os apresentados anteriormente.

Quadro 3 - Indicadores de Alfabetização Científica

\begin{tabular}{|l|l|}
\begin{tabular}{|l} 
Indicadores de \\
Alfabetização Científica
\end{tabular} & \multicolumn{1}{c|}{ Descrição } \\
\hline Listagem de materiais & $\begin{array}{r}\text { Aparece quando os materiais utilizados na atividade são } \\
\text { apresentados. Pode aparecer como uma lista ou na } \\
\text { descrição da montagem das atividades. }\end{array}$ \\
\hline Argumentos & $\begin{array}{c}\text { São encontrados quando uma afirmação é feita baseada } \\
\text { em dados, que podem ser empíricos ou não, e estes } \\
\text { levam a uma conclusão. Comumente são encontradas } \\
\text { justificativas que avalizam a relação entre a conclusão e } \\
\text { os dados que levam a ela, mas esta justificativa não é } \\
\text { condição sine qua non. Aparecem para defender e } \\
\text { justificar opiniões. }\end{array}$ \\
\hline
\end{tabular}

Fonte: Del-Corso (2014).

Del-Corso (2014) ao propor o indicador "Listagem de materiais" correlaciona com o primeiro eixo dos Indicadores de Alfabetização Cientifica de Sasseron e Carvalho (2008), que trazem Indicadores de Alfabetização Científica para trabalhar com os dados de uma investigação, constituído por Seriação, Organização e Classificação de Informações, compreende os indicadores relacionados ao trabalho direto com os dados empíricos ou com as bases por meio das quais se compreende um assunto ou situação.

Ao correlacionar, o indicador denominado de "argumento", Del-Corso (2014) relaciona esse indicador aos Indicadores para entendimento da situação analisada de Sasseron e Carvalho (2008) que compreende aponta como elementos o Teste de Hipóteses, Justificativa, Previsão e Explicação. Estes estão vinculados à procura do entendimento da situação analisada - sendo que, de acordo com Sasseron (2008), os três últimos se relacionam fortemente e podem explicitar um padrão de acontecimentos passível de expansão a outras situações.

Pizarro e Lopez Júnior (2015) também buscaram Indicadores da Alfabetização Científica na qual sua caracterização compreende o fazer científico como algo indissociável do ser social atuante e consciente como apresentado no Quadro 4: 
Quadro 4-Indicadores de Alfabetização Científica na perspectiva social

\begin{tabular}{|c|c|}
\hline $\begin{array}{l}\text { Indicadores de } \\
\text { Alfabetização } \\
\text { Científica }\end{array}$ & Descrição \\
\hline Articular ideias & $\begin{array}{l}\text { Surge quando o aluno estabelece relações, seja oralmente ou por } \\
\text { escrito, entre o conhecimento teórico aprendido em sala de aula, } \\
\text { a realidade vivida e o meio ambiente no qual está inserido. }\end{array}$ \\
\hline Investigar & $\begin{array}{l}\text { Ocorre quando o aluno se envolve em atividades nas quais ele } \\
\text { necessita apoiar-se no conhecimento científico adquirido na } \\
\text { escola (ou até mesmo fora dela) para tentar responder a seus } \\
\text { próprios questionamentos, construindo explicações coerentes e } \\
\text { embasadas em pesquisas pessoais que leva para a sala de aula e } \\
\text { compartilha com os demais colegas e com o professor. }\end{array}$ \\
\hline Argumentar & $\begin{array}{c}\text { Está diretamente vinculado com a compreensão que o aluno tem } \\
\text { e a defesa de seus argumentos, apoiado, inicialmente, em suas } \\
\text { próprias ideias, para ampliar a qualidade desses argumentos a } \\
\text { partir dos conhecimentos adquiridos em debates em sala de aula, } \\
\text { e valorizando a diversidade de ideias e os diferentes argumentos } \\
\text { apresentados no grupo. }\end{array}$ \\
\hline Ler em Ciências & $\begin{array}{l}\text { Trata-se de realizar leituras de textos, imagens e demais suportes } \\
\text { para o reconhecimento de características típicas do gênero } \\
\text { científico e para articular essas leituras com conhecimentos } \\
\text { prévios e novos, construídos em sala de aula e fora dela. }\end{array}$ \\
\hline $\begin{array}{c}\text { Escrever em } \\
\text { Ciências }\end{array}$ & $\begin{array}{l}\text { Envolve a produção de textos pelos aluno que considera não } \\
\text { apenas as características típicas de um texto científico mas } \\
\text { avança também no posicionamento crítico diante de variados } \\
\text { temas em Ciências e articulando, em sua produção, os seus } \\
\text { conhecimentos, argumentos e dados das fontes de estudo. }\end{array}$ \\
\hline Problematizar & $\begin{array}{l}\text { Surge quando é dada ao aluno a oportunidade de questionar e } \\
\text { buscar informações em diferentes fontes sobre os usos e } \\
\text { impactos da Ciência em seu cotidiano, na sociedade em geral e } \\
\text { no meio ambiente. }\end{array}$ \\
\hline Criar & $\begin{array}{c}\text { É explicitado quando o aluno participa de atividades em que lhe é } \\
\text { oferecida a oportunidade de apresentar novas ideias, } \\
\text { argumentos, posturas e soluções para problemáticas que } \\
\text { envolvem a Ciência e o fazer científico discutidos em sala de aula } \\
\text { com colegas e professores. }\end{array}$ \\
\hline Atuar & $\begin{array}{l}\text { Aparece quando o aluno compreende que é um agente de } \\
\text { mudanças diante dos desafios impostos pela Ciência em relação à } \\
\text { sociedade e ao meio ambiente, tornando-se um multiplicador dos } \\
\text { debates vivenciados em sala de aula para a esfera pública. }\end{array}$ \\
\hline
\end{tabular}

Fonte: Pizarro e Lopez Júnior (2015). 
Pizarro e Lopez Júnior (2015) buscaram uma proposta de ensino, utilizando a pesquisa prática, começando a partir da premissa de que o conhecimento nas Ciências Naturais é construído por uma investigação que incorpora metodologia científica na elaboração e análise de dados obtidos a partir de atividades experimentais, interpretação de resultados, proposições de formulação e conclusões sobre o fenômeno natural investigado. Assim, consideraram que a aprendizagem baseada em inquéritos pode ser realizada por um trabalho baseado em ideias de ensino e ciência no processo de construção e reconstrução do conhecimento científico; pode ser incluído, por exemplo, no contexto da prática científica, fornecendo aos alunos a experiência de práticas científicas e formas como um cientista atua em seu local de trabalho (GUISASOLA et al., 2006; SMITHENRY, 2010). Assim, a proposta de aprendizagem baseada em inquérito visa proporcionar o contato dos alunos os conceitos de processos de apropriação, práticas epistêmicas e discursivas da comunidade científica das Ciências Naturais.

Partindo dos pressupostos teóricos apresentados com as características que respaldam os elementos de desenvolvimento do senso crítico, analítico e científico que sustentam essa pesquisa e que precisam ser confrontados e analisados para compreender como desdobra o desenvolvimento destes pelo processo de ensino e aprendizagem, ou seja, como é possível identificar elementos que evidenciem o desenvolvimento do senso crítico, analítico e científico a partir das inferências dos estudantes do 6ㅇ ano do Ensino Fundamental através da Educação Ambiental?

\section{METODOLOGIA}

A pesquisa foi aplicada utilizou da Pesquisa Participante como método, que segundo Esteban (2010) compreende num processo compartilhado de desconstrução, construção e reconstrução de conhecimentos em uma ação transformadora e emancipadora. Além disso, o professor busca entender como os estudantes compreendem suas próprias situações e como constroem suas realidades, combinando ao mesmo tempo a participação ativa dos estudantes, as conversas informais e as análises das atividades desenvolvidas.

A pesquisa foi efetivada no Colégio Estadual Júlia Wanderley no Município de Curitiba - Paraná. Participaram deste estudo 20 estudantes do 60 ano do Ensino Fundamental, sendo 11 meninos (55\%) e 9 meninas (45\%), com idade entre 11 e 12 anos, denominados pelas siglas " $A$ " (Aluno A01, A02, etc.) estando em consonância com os documentos Termo de Assentimento Livre esclarecido para menores de 18 anos - TALE, Termo de Consentimento livre e esclarecido - TCLE, respeitando a privacidade e o sigilo do educando conforme termo de aprovação do Comitê de ética № 60796516.0000.5547.

Dessa forma, foi proposto uma Sequência Didática (SD) tendo como temática a Pegada Ecológica do Lixo, organizada com diferentes instrumentos, tais como aulas expositivas, ilustrativas, demonstrativas, dialogadas, práticas e visita a campo, para o estudo de temas que contemplassem o lixo como tema gerador de conhecimento de forma contextualizada que pudesse ser interessante para o aluno. Estas atividades têm se mostrado relevantes pela sua capacidade de motivar o aluno a participar espontaneamente da aula, por privilegiar o trabalho em grupo, a relação dialógica entre professores e alunos, além de promover a cooperação, a socialização e instigar a curiosidade infantil (PEDROSO, 2009). 
Para a coleta de dados foi utilizado um questionário que foi validado por professores do Programa de Pós-Graduação em Formação Científica, Educacional e Tecnológica-FCET e aprovado no marco do projeto do Comitê de Ética e Pesquisa - CEP.

Primeiramente foi apresentado aos estudantes a etapas a ser realizadas com a aplicação da Sequência Didática sobre Educação Ambiental com enfoque na Pegada Ecológica do Lixo. Dentre as temáticas abordadas na Sequência Didática estavam: Resíduos Sólidos, Classificação dos tipos de lixo, Tipos de Lixeira, Reutilização, Política dos 3R's, Reciclagem, Coleta Seletiva, Destino final do lixo, Lixo orgânico, Compostagem.

Na aplicação da Sequência Didática sobre a Pegada Ecológica do lixo - PEL, inicialmente foram realizadas rodas de conversa para perceber os conhecimentos prévios e posteriormente perceber a construção da Alfabetização Científica, confrontando diferentes opiniões e novos posicionamentos, a partir das ferramentas disponíveis nas aulas teóricas e práticas estimulando-os, assim, à criatividade e ao "saber ouvir", dando oportunidade de expressarem suas opiniões, dúvidas, anseios. Isso possibilitou além da exposição de suas vivências e experiências com a temática do lixo promovendo a compreensão de ações e atitudes a fim de possibilitar reflexões, envolvimento, sensibilização e mudança de atitude para o cuidado com o Meio Ambiente.

O questionário semiestruturado foi aplicado antes e após a Sequência Didática, onde os estudantes responderam questões relativas ao conteúdo trabalhado na mesma, para que então fosse possível perceber as respostas que evidenciassem elementos de desenvolvimento crítico, analítico e científico dos participantes. Houve o cuidado de não interferir nas respostas, por se entender que esses momentos da pesquisa são fundamentais para que os dados coletados sejam os mais genuínos possíveis e para não mascarar o processo de análise.

Por fim, a análise do questionário e dos dados a partir da observação da aplicação da Sequência Didática sobre a Educação Ambiental ocorreu por meio da análise qualitativa das inferências dos dados na perspectiva da análise de conteúdo que segundo Bardin, a produção de inferências não é somente produzir suposições subliminares acerca de determinada mensagem, mas em embasá-las com pressupostos teóricos de diversas concepções de mundo e com as situações concretas de seus produtores ou receptores. Assim a análise de conteúdo é "um método empírico que depende do tipo de "fala" a que se dedica e do tipo de interpretação que se pretende como objetivo" (BARDIN, 2011, p. 30).

A interpretação dos resultados se deu pela descrição das respostas do questionário dos estudantes começando pela leitura dos materiais e agrupando por significações baseado em elementos que apontam Indicadores de Alfabetização Científica. No tratamento dos resultados nos dados brutos, buscouse torná-los significativos e válidos. Esta interpretação foi além do conteúdo manifesto dos documentos, pois interessa ao pesquisador o conteúdo latente, o sentido que se encontra por trás do imediatamente apreendido.

Assim fecha-se o processo de Análise de Conteúdo, o qual esta centrada nas categorias prévias por temática determinada como senso crítico, analítico e científico, embasado a luz da literatura científica exposto por Zoller (1993); Mortimer e Santos (2001); Amaral (2006); Sasseron e Carvalho (2008); Carraher (2011); Del-Corso (2014); Pizarro e Lopes (2015). 


\section{RESULTADOS E DISCUSSÃO}

Nesta seção são apresentados os dados que evidenciam o desenvolvimento do senso crítico, analítico e científico dos participantes a luz da teoria, que emergiram com a aplicação da Sequência Didática do Recurso Educacional Aberto "Pegada Ecológica do Lixo". Para tais análises primeiramente foram estabelecidas categorias para que se pudesse destacar a partir da pré-analise, leitura flutuante e por meio da inferência a evidência destes elementos.

Na Tabela 1 são apresentadas as respostas dos estudantes que demonstram o desenvolvimento do senso crítico baseado nos pressupostos teóricos descritos por Carraher (2011). Essas características podem ser observadas nas questões selecionadas do Questionário Inicial (Q.I) e Questionário Final (Q.F). Evidenciaramse nas respostas dos alunos características como a consciência pragmática, coerência de posições, habilidade para perceber a estrutura de argumentos em linguagem natural, habilidade de pensar logicamente, perspicácia, distinção entre questões e fatos, de valor de questões conceituais.

Tabela 1 - Desenvolvimento do senso crítico dos estudantes

\begin{tabular}{|c|c|c|c|}
\hline Categoria & Subcategorias & Componentes & Exemplos de Respostas \\
\hline \multirow{10}{*}{ Senso crítico } & \multirow{6}{*}{$\begin{array}{l}\text { Habilidade de } \\
\text { pensar } \\
\text { logicamente, } \\
\text { ou ainda, } \\
\text { habilidade de } \\
\text { perceber a } \\
\text { estrutura dos } \\
\text { argumentos } \\
\text { em linguagem } \\
\text { natural. }\end{array}$} & \multirow{6}{*}{$\begin{array}{c}\text { Quadro } 10 \\
\text { (Q.F) Quais } \\
\text { seriam as } \\
\text { atitudes para } \\
\text { que a } \\
\text { reciclagem } \\
\text { pudesse ser } \\
\text { compreendida } \\
\text { como } \\
\text { essencial para } \\
\text { a sociedade? }\end{array}$} & $\begin{array}{l}\text { A05-“Fazer em casa a } \\
\text { separação do lixo e resíduos, } \\
\text { reutilizar, por exemplo, } \\
\text { garrafas, pois os recursos } \\
\text { naturais são finitos". }\end{array}$ \\
\hline & & & $\begin{array}{c}\text { A09-“Jogar menos lixo fora, } \\
\text { reutilizar o que pode ser } \\
\text { reutilizado”. }\end{array}$ \\
\hline & & & $\begin{array}{c}\text { A14-“Usar menos coisas, } \\
\text { reutilizar e reciclar". }\end{array}$ \\
\hline & & & $\begin{array}{c}\text { A16-“Que as pessoas } \\
\text { jogassem/produzisse menos } \\
\text { lixo". }\end{array}$ \\
\hline & & & $\begin{array}{c}\text { A19-“Fazer campanhas, } \\
\text { cartazes, propagandas e } \\
\text { muito mais". }\end{array}$ \\
\hline & & & $\begin{array}{c}\text { A20-"Divulgação e campanha } \\
\text { de reciclagem". }\end{array}$ \\
\hline & \multirow{4}{*}{$\begin{array}{l}\text { Perspicácia, } \\
\text { perceber além } \\
\text { do que é dito } \\
\text { explicitamente, } \\
\text { descobrindo as } \\
\text { ideias } \\
\text { subentendidas } \\
\text { e subjacentes. }\end{array}$} & \multirow{4}{*}{$\begin{array}{l}\text { Quadro } 11 \\
\text { (Q.F) Quais } \\
\text { medidas } \\
\text { seriam } \\
\text { necessárias } \\
\text { para } \\
\text { prolongar a } \\
\text { vida útil dos } \\
\text { Aterros } \\
\text { Sanitários? }\end{array}$} & $\begin{array}{c}\text { A13/A16-“Reduzir o } \\
\text { consumo, menor produção } \\
\text { de lixo”. }\end{array}$ \\
\hline & & & $\begin{array}{l}\text { A02-“Realizar compostagem, } \\
\text { reutilizar materiais". }\end{array}$ \\
\hline & & & $\begin{array}{l}\text { A04-“Separar mais o lixo, } \\
\text { reutilizar mais objetos". }\end{array}$ \\
\hline & & & $\begin{array}{l}\text { A05-“Reutilizar materiais que } \\
\text { podem ser reutilizados, } \\
\text { separar o lixo em reciclável e } \\
\text { não reciclável e os recicláveis } \\
\text { enviar para indústrias de } \\
\text { reciclagem”. }\end{array}$ \\
\hline
\end{tabular}


A01-"Devemos cuidar do Meio Ambiente/Planeta". A02-"Importante para as crianças aprenderem desde cedo a não fazer o que os

$\begin{array}{cc}\text { Consciência } & \text { Quadro 05 } \\ \text { pragmática } & \text { (Q.F) } \\ \text { com meio de } & \text { O que você } \\ \text { alcançar } & \text { acha de } \\ \text { objetivos e } & \text { aprender } \\ \text { influir sobre os } & \text { Educação } \\ \text { outros. } & \text { Ambiental na } \\ & \text { escola? }\end{array}$
adultos fizeram. Jogar lixo nas ruas e jogar lixo no lugar errado".

A03-“Acho muito bom porque as pessoas não se preocupam com o meio ambiente e isso tem que mudar".

A08-“Importante para não cometer os mesmos erros".

A10- "Sim porque as crianças tem que saber o que está acontecendo com o nosso Planeta".

A03- "Poluição, degradação, infecção".

A04-“Contaminação da água subterrânea, lençol freático,

Quadro 06

Distinção entre questões de fato, de valor e questões conceituais.
Quais as consequências que o lixo pode trazer ao Meio Ambiente? poluição do ar".

A05-“Poluição, desgaste de recursos naturais".

A07-“Alagamento, Poluição dos rios, matar os seres vivos dentro da água, poluição do planeta".

A08-"Maltratam os animais, entope bueiros, causam enchentes".

A10-"Trazer doenças para os seres vivos".

Fonte: Marques e Xavier (2018).

Na Tabela 1 verificou-se o desenvolvimento do senso crítico dos alunos a partir de elementos apresentados conforme as inferências analisadas, nas quais se destaca a consciência pragmática, coerência de posições, habilidade para perceber a estrutura de argumentos em linguagem natural, habilidade de pensar logicamente, perspicácia, distinção entre questões e fatos, de valor de questões conceituais.

Para Marques e Xavier (2018) o desenvolvimento do senso crítico está delineado por algumas vertentes que apontam a elucidação da sua forma de reconhecimento e apreciação do uso prático da linguagem como meio de alcançar objetivos e influir sobre os outros a qual se denomina por consciência pragmática.

Foi possível observar que os elementos que evidenciam o senso crítico adquirido na aplicação da Sequência Didática "Pegada Ecológica do Lixo" possibilitaram que os estudantes tivessem 
fazendo que por meio desta argumentação os estudantes pudessem fazer conclusões por meio do conhecimento adquirido. Leva-se em consideração o fato que quando alguém apresenta um argumento seja uma criança, um professor universitário, pedreiro ou filósofo, usa premissas, às vezes chamadas evidências, para defender ou fundamentar sua conclusão. Pode-se afirmar que as evidências formadas como ponto de partida é o que dão segurança para tornar explícita sua argumentação (MARQUES; XAVIER, 2018, p. 147).

Os autores ainda defendem que

a percepção da consciência pragmática no sujeito crítico permite a construção da sua argumentação, característica esta que dá ao estudante a habilidade de transpor a sua coerência de posições sistematizando sua posição diante de uma problemática (MARQUES; XAVIER, 2018, p.147).

Pode-se perceber ainda elementos que conferem a

\begin{abstract}
habilidade de perceber a estrutura de argumentos em linguagem natural e isso se dá por meio da sua experiência, da sua sensibilização e a observação que permitiu estabelecer associações entre sua aprendizagem e dispor explicações que fundamentem seu ponto de vista (MARQUES; XAVIER, 2018, p. 147).
\end{abstract}

A perspicácia como tendência de perceber além do que é dito explicitamente, pela apresentação das ideias subentendidas e subjacentes, despertando o entendimento para um sentido global dos fatos foi evidenciado pelos estudantes com indicadores de senso crítico. As ideias subentendidas não estão declaradas explicitamente, mas fazem parte da íntegra das comunicações. Para entendermos a comunicação na sua íntegra, é preciso perceber além de considerações meramente lógicas e semânticas. Existem ideias necessárias para compreendermos adequadamente o significado das comunicações e cuja descoberta exige uma análise daquilo em que se baseia o raciocínio (MARQUES; XAVIER, 2018, p. 147).

Marques e Xavier (2018) inferem que por meio desta análise muitas ideias são ou estão implícitas, contudo é necessário considerar o uso da perspicácia para raciocinar sobre fenômenos sociais que apresentam múltiplas facetas e, por conseguinte, múltiplas perspectivas. Baseados nessas perspectivas os estudantes demonstram uma diversidade de expressões de ideias transcendendo os problemas locais para ter uma perspectiva mais ampla. Marques e Xavier (2018) afirma que há uma lógica distinta nas entrelinhas chamada de lógica aberta à medida que leva em consideração as múltiplas facetas dos fenômenos em estudo e existe a lógica fechada na medida em que não considera aspectos importantes dos fenômenos. Deve-se enfatizar aqui que o desenvolvimento do senso crítico num determinado campo exige conhecimento mais intimo das questões conceituais, das tradições dos conflitos atuais ou qual sua relação com a interpretação de significados daquele campo do conhecimento (CARRAHER, 2011).

O desenvolvimento do senso analítico foi analisado partindo das premissas respaldas por Zoller (1993), apontado por Mortimer e Santos (2001) e por Amaral (2006) que apresentam características para o desenvolvimento do senso analítico e a capacidade em analisar e emitir pareceres sobre determinando tema. Essas características do desenvolvimento analítico dos participantes podem ser 
observadas nas respostas relacionadas às questões do Questionário Inicial (Q.I) e Questionário Final (Q.F) como mostra a Tabela 2.

Tabela 2 - Desenvolvimento do senso analítico dos estudantes

\begin{tabular}{|c|c|c|c|}
\hline Categoria & Subcategorias & Componentes & Exemplos de respostas \\
\hline \multirow{8}{*}{$\begin{array}{l}\text { Senso } \\
\text { analítico }\end{array}$} & $\begin{array}{l}\text { Geração de novas } \\
\text { opções; visão } \\
\text { global. }\end{array}$ & $\begin{array}{c}\text { Figura } 6 \text { A - } 6 \text { B } \\
\text { Atividades e } \\
\text { temas } \\
\text { relacionados á } \\
\text { Educação } \\
\text { Ambiental na } \\
\text { escola. }\end{array}$ & $\begin{array}{c}\text { Q.I - } 9 \text { relacionadas ao lixo } \\
\text { - } 1 \text { cuidado com natureza e flores } \\
\text { - } 10 \text { não responderam } \\
\text { Q.F - } 11 \text { relacionadas ao lixo } \\
\text { - } 1 \text { Desmatamento } \\
\text { - } 1 \text { Cuidar e Proteger a natureza } \\
\text { - } 1 \text { Respeitar o Meio Ambiente } \\
\text { - } 1 \text { Pegada Ecológica } \\
\text { - } 1 \text { Poluição }\end{array}$ \\
\hline & \multirow{4}{*}{$\begin{array}{l}\text { Reconhecimento } \\
\text { da existência de } \\
\text { um problema; } \\
\text { Tomada de } \\
\text { responsabilidade; } \\
\text { Lidar com } \\
\text { ambiguidades, } \\
\text { conflitos e dados, } \\
\text { Visão de futuro. }\end{array}$} & $\begin{array}{l}\text { Quadro } 04 \text { (Q.I) } \\
\text { O que você } \\
\text { entende por } \\
\text { Educação } \\
\text { Ambiental? }\end{array}$ & $\begin{array}{l}\text { A19-“Cuidar do nosso meio } \\
\text { ambiente, sem poluir, reciclando, } \\
\text { mas infelizmente muitas pessoas } \\
\text { não nos ajudam”. } \\
\text { A18-“Não jogar lixos nas ruas, não } \\
\text { destruir meio ambiente, assim } \\
\text { você estará fazendo sua parte e } \\
\text { também ter uma cidade limpa e } \\
\text { bem cuidada”. }\end{array}$ \\
\hline & & \multirow{3}{*}{$\begin{array}{l}\text { Quadro } 05 \text { (Q.F) } \\
\text { O que você acha } \\
\text { de aprender } \\
\text { Educação } \\
\text { Ambiental na } \\
\text { escola? }\end{array}$} & $\begin{array}{l}\text { A02-“Importante para as crianças } \\
\text { aprenderem desde cedo a não } \\
\text { fazer o que os adultos fizeram. } \\
\text { Jogar lixo nas ruas e jogar lixo no } \\
\text { lugar errado.” }\end{array}$ \\
\hline & & & $\begin{array}{l}\text { A05-“Bom, pois assim as próximas } \\
\text { gerações podem ajudar a cuidar } \\
\text { do meio ambiente”. }\end{array}$ \\
\hline & & & $\begin{array}{l}\text { A10-“Sim porque as crianças tem } \\
\text { que saber o que está } \\
\text { acontecendo com o nosso } \\
\text { planeta”. }\end{array}$ \\
\hline & \multirow{3}{*}{$\begin{array}{l}\text { Aprender com as } \\
\text { experiências, } \\
\text { Discernimento; } \\
\text { Compreensão da } \\
\text { essência factual } \\
\text { do conhecimento } \\
\text { e conceitos } \\
\text { envolvidos; }\end{array}$} & \multirow{2}{*}{$\begin{array}{l}\text { Quadro } 09 \text { (Q.I) } \\
\text { Você acha que } \\
\text { todo lixo pode } \\
\text { ser reciclado? }\end{array}$} & $\begin{array}{l}\text { A11-“Não, tem coisas que não } \\
\text { podem ser reciclados: pilhas } \\
\text {,baterias, carregadores” }\end{array}$ \\
\hline & & & $\begin{array}{l}\text { A16-“ Não porque tem alguns que } \\
\text { não podem ser separados. }\end{array}$ \\
\hline & & $\begin{array}{l}\text { Figura } 7 \text { (Q.I) } \\
\text { Qual o critério } \\
\text { de escolha de } \\
\text { produtos para o } \\
\text { consumo? }\end{array}$ & $\begin{array}{l}\text { 43\% Procuram considerar preço e } \\
\text { qualidade; } \\
\text { 32\% Escolhem produtos que } \\
\text { venham em embalagens } \\
\text { recicláveis e que respeitam } \\
\text { critérios ambientais e sociais. }\end{array}$ \\
\hline
\end{tabular}

Fonte: Marques e Xavier (2019b).

Observa-se que pelas respostas dos estudantes que estes apresentam elementos que evidenciam o desenvolvimento do senso analítico. Marques e Xavier (2019b) apontam os elementos como: reconhecimento da existência de um problema, geração de novas opções, tomada de responsabilidade, lidar com 
ambiguidades, conflitos e dados, visão de futuro, aprender com as experiências, discernimento, compreensão da essência factual do conhecimento e conceitos envolvidos, análise dos dados pela sua racionalidade ou tomada de decisão, interpretação de dados pela sua intuição, raciocínio lógico, pensamento analítico. No entanto se verificou que a frequência das respostas relacionadas ao senso analítico foram maiores no (Q.I).

Marques e Xavier (2019b) afirmam de acordo com a Tabela 2, ser possível perceber e fazer uma análise comparativa estabelecendo ligação entre o antes e o depois da aplicação da Sequência Didática ampliando seus conceitos e ainda gerando novas opções para demonstrar sua compreensão sobre a temática estudada. Esse fato se destaca pela relevância de reconhecer a existência de um problema ou outros problemas que não tinha clareza para se expressar.

A partir das respostas dos estudantes pode-se constatar que os estudantes "adotam posturas como a tomada de responsabilidade, permitindo ainda uma análise de como lidar com ambiguidade, conflitos, dados, além de conceber uma perspectiva de visão de futuro que assomam aos dados que tinham anteriormente, tornando sua visão global, além da extração de informações relevantes obtidas da sua relação com seu posicionamento frente à problemática ambiental" (MARQUES e XAVIER, 2019b).

Marques e Xavier (2019b) destacam que o posicionamento é uma das características para a tomada de decisão, fator intrínseco ao senso analítico; percebe-se a partir das respostas dos estudantes a sua aptidão para aprender com as experiências e incrementar o discernimento demonstrando a compreensão da essência factual dos conhecimentos e conceitos envolvidos. É por meio desta congruência e coesão que se destaca a racionalidade demonstrada em forma de exemplos dados pela sua interpretação ou raciocínio tornando parte do seu pensamento.

O desenvolvimento do senso científico foi analisado com base nas características descritas ou destacadas nas respostas dos estudantes, tais como: raciocínio lógico, explicação, justificativa e Classificação de Informações. As características selecionadas estão fundamentadas por Sasseron e Carvalho (2008) e Pizarro e Lopez Júnior (2015) nos Indicadores de Alfabetização científica e do senso científico que podem ser mais observados nas questões do Questionário Inicial (Q.I) e Questionário Final (Q.F) como mostra a Tabela 3 a seguir:

Tabela 3 - Desenvolvimento senso científico dos estudantes

\begin{tabular}{|c|c|c|c|}
\hline Categoria & Subcategorias & Componentes & Exemplos de respostas \\
\hline \multirow[t]{2}{*}{$\begin{array}{c}\text { Senso } \\
\text { científico }\end{array}$} & \multirow[t]{2}{*}{$\begin{array}{l}\text { Organização e } \\
\text { Classificação de } \\
\text { informações. }\end{array}$} & $\begin{array}{c}\text { Figura } 14 \text { (Q.I / Q.F) } \\
\text { Associe o tipo de } \\
\text { lixeira com a cor da } \\
\text { lixeira. }\end{array}$ & $\begin{array}{c}\text { (Q.I) - 60\% associações } \\
\text { erradas } \\
-40 \% \text { associações corretas } \\
\text { (Q.F) - 61\% associações } \\
\text { corretas } \\
\text { - 33\% associações erradas } \\
\text { - 06\% não respondeu }\end{array}$ \\
\hline & & $\begin{array}{c}\text { Figura } 10 \text { (Q.I) } \\
\text { O que significa os } 3 \\
\text { R's? }\end{array}$ & $\begin{array}{c}\text { (Q.I)14 acertos } \\
\text { (Reduzir, Reutilizar, Reciclar) }\end{array}$ \\
\hline
\end{tabular}




\section{Quadro 08 (Q.I) \\ Você sabe o que é Reciclagem?

$\begin{array}{lc}\text { Raciocínio } & \text { Figura } 11 \text { (Q.I) } \\ \text { Lógico e } & \text { O que é lixo } \\ \text { raciocínio } & \text { orgânico? } \\ \text { proporcional; } & \\ \text { Explicação. } & \end{array}$

Figura $12 \mathrm{~b}$ (Q.I)

Você sabe o que é compostagem?
A04-“É o processo de
transformação do lixo em outro objeto"

10\% Alimentos que podem virar adubo

$40 \%$ Restos de comida $5 \%$ borra de café, cascas de ovos, frutas, restos de comida, folhas.

- 3 Fazer adubo com lixo orgânico

-1 Processo de transformação do lixo orgânico em adubo. - 16 não sabiam o que era. A04-Contaminação da água subterrânea, lençol freático, poluição do ar.

Seriação de Informações; classificação de Informações; Levantamento de hipóteses.
Quadro 6 (Q.F) Quais as consequências que o lixo pode trazer ao Meio Ambiente?

A07-Alagamento, Poluição dos rios, matar os seres vivos dentro da água, poluição do planeta.

A08-Maltratam os animais, entope bueiros, causam enchentes.

A10-Trazer doenças para os seres vivos.

A05-Fazer em casa a separação do lixo e resíduos, reutilizar, por exemplo, garrafas, pois os recursos naturais são finitos. A07- Reciclar objetos sem utilidade, colocar o lixo no lixo, não deixar o lixo nas ruas, porque pode um cachorro abrir o saco do lixo.

Justificativa.

Explicação;

\section{Quadro 10 (Q.F)}

Quais seriam as atitudes para que a reciclagem pudesse ser compreendida como essencial para a sociedade?

\section{Quadro 11 (Q.F) \\ Quais medidas \\ seriam necessárias para prolongar a vida útil dos Aterros \\ Sanitários?}

A05-Reutilizar materiais que podem ser reutilizados, separar o lixo sem reciclável e não reciclável, os recicláveis enviar para indústria de reciclagens.

Fonte: Marques e Xavier (2019a).

Marques e Xavier (2019a) consideram que as características do desenvolvimento do senso científico como raciocínio lógico, explicação, justificativa e classificação de informações verificou-se que em geral os estudantes demonstram a compreensão básica de termos, conhecimentos e conceitos científicos fundamentais e a importância deles. No entanto, antes da aplicação da sequência didática parte deles não conhecia o significado dos 3 R's ou sabia associar corretamente a lixeira e sua cor. Além disso, antes da aplicação da Sequência Didática relacionavam o lixo orgânico apenas com restos de comida e não sabiam o que era compostagem. 
Constata-se que a compreensão dos conceitos científicos está associada à classificação de informações onde os estudantes ordenam os dados, segundo as características dos mesmos, assim como o raciocínio lógico que compreende o modo como às ideias são desenvolvidas e apresentadas, relacionando-se, pois, diretamente com a forma como o pensamento é exposto.

Ressalta-se ainda que os conceitos do cotidiano, alternativos, espontâneos, pré-conceitos adquiridos pelo senso comum quando tratados e tomam significado para o estudante, vão dando lugar aos conceitos científicos. No entanto, esses conhecimentos prévios oriundos do senso comum são importantes para sua ressignificação por meio da ação dialógica através da linguagem e da percepção sendo indispensáveis para o processo de formação de conceitos científicos; a percepção das diferenças ocorre mais cedo do que a das semelhanças porque esta exige uma estrutura de generalização e de conceitualização mais avançada; o desenvolvimento dos processos que resultam na formação de conceitos começa na infância. Têm-se ainda que as funções intelectuais que formam a base psicológica do processo de formação de conceitos amadurecem e se tornam mais evidentes na adolescência; a formação de conceitos é o resultado de uma atividade complexa, em que todas as funções intelectuais básicas (atenção deliberada, memória lógica, abstração, capacidade para comparar e diferenciar) tomam parte; "os conceitos novos e mais elevados transformam o significado dos conceitos inferiores" (VIGOTSKY, 1991, p. 93).

Lorenzetti e Delizoicov (2001) contribuem ainda ao afirmar de forma objetiva que os assuntos científicos devem ser cuidadosamente apresentados, discutidos, permitindo que essa compreensão dos significados possa ser aplicada para que o estudante tenha o entendimento do mundo. Isso porque, está é uma necessidade em nossa sociedade que se baseia em compreender conceitos-chave como forma de poder entender até mesmo pequenas informações e situações do dia-a-dia.

Marques e Xavier (2019a) pontuam que é preciso considerar em todo esse processo de problematização e sistematização do conhecimento cientifico que as ideias ou senso comum que os alunos trazem para a escola são necessárias para a construção de significados a partir de seus conhecimentos prévios. Dessa forma,

\begin{abstract}
Suas experiências culturais e familiares não podem ser negadas. Essas ideias devem ser aceitas para progressivamente evoluírem, serem substituídas ou transformadas. A resistência para substituir alguns conceitos só é superada se o conceito científico trouxer maior satisfação: for significativo, fizer sentido e for útil. Os conceitos científicos com maior grau de aplicabilidade, que explicam um maior número de situações e resolvem um maior número de problemas, facilitam a mudança. O diálogo com os alunos possibilita o diagnóstico de suas ideias em vários momentos da aprendizagem. Da mesma forma, a interação entre parceiros e a observação dos diálogos travados entre eles. É importante lembrar que o ensino sistemático e explícito na escola deve levar o aluno a reconceitualizações e, principalmente, desenvolver formas de pensar que se estendam para outras áreas do conhecimento e para situações que transcendem a sala de aula (MARQUES; XAVIER, 2019a, p. 2606).
\end{abstract}

É uma preocupação para a alfabetização científica a necessidade de que os alunos consigam não apenas aprender o conteúdo de Ciências em si, mas que também saibam dar-Ihe significado. Para isso, faz-se necessário um ensino que ofereça aos alunos a oportunidade de desenvolver habilidades cognitivas que lhes permitam articular o conhecimento teórico com a sua realidade, ou seja, de forma contextualizada e os fenômenos nela observados. 
Ao refletir sobre esses aspectos deve-se cada vez mais inibir a mera transmissão de informações e estimular um ensino que faça com que os estudantes sintam-se parte dele e por meio deste pertencimento usufruam da leitura e interpretação básicas para o seu desenvolvimento, bem como habilidades investigativas para alcançar um nível sofisticado de conhecimento científico: habilidades de percepção; habilidades instrumentais; habilidades de pensamento; habilidades de construção conceitual; habilidades de construção metodológica; habilidades de construção social do conhecimento; e habilidades meta-cognitivas (BAYARDO, 2003, p. 76).

Marques e Xavier (2019a) reiteram que as discussões sobre a temática apresentadas, levarão eles a usarem as habilidades próprias do "fazer científico" na qual se entende que os alunos participantes destas discussões estão em processo de Alfabetização Cientifica. A participação e envolvimento dos estudantes durante a aplicação da Sequência Didática "Pegada ecológica do lixo" aqui analisada nos permitiram evidenciar seu desenvolvimento crítico, analítico e científico.

Destaca-se que segundo as respostas obtidas no Questionário Inicial (Q.I) e no Questionário Final (Q.F), após a aplicação da Sequência Didática pode-se perceber e analisar que os estudantes apresentam evidências de desenvolvimento do senso crítico quando apresentam melhora na capacidade argumentativa, senso analítico considerando além dos termos quantitativos a capacidade de receber informações de várias fontes e organiza-las de forma racional e senso científico com a construção e utilização de termos científicos ou se apropriar de indicadores como organização de informações, justificativa, explicação que indicam a apropriação do conhecimento e Alfabetização Cientifica.

\section{CONSIDERAÇÕES FINAIS}

O presente trabalho surgiu de inquietações, questionamentos e reflexões acerca da Educação Ambiental como tema transversal no ensino e que, muitas vezes, está ausente nas discussões da organização escolar ficando implícito, ou raramente explícito, no processo formativo dos estudantes. Relaciono esta exposição aos objetivos sociais e políticos da Educação Ambiental em apresentar não somente a importância da Educação Ambiental, mas neste trabalho investigar como é possível identificar elementos do desenvolvimento do senso crítico, analítico e científico em alunos do 60 anos do Ensino Fundamental na promoção da Educação Ambiental contribuindo com o Ensino de Ciências.

Percebeu-se que os estudantes não estão familiarizados com conceitos relacionados á temática do lixo mesmo fazendo parte do seu cotidiano. Para tanto, nota-se a importância de se abordar os conteúdos relacionados à temática ambiental na construção do conhecimento científico, valorizando a autonomia da reflexão e interpretações de questões-problemas, além de garantir a vivência dos estudantes com a temática ambiental de forma contextualizada relacionando estes conceitos nas implicações da sociedade que são ocasionados pelo lixo/resíduo. Com isso, nota-se que houve um estímulo e despertou a curiosidade e a participação ativa dos estudantes para a construção do conhecimento a partir da ação de minimizar impactos ambientais negativos no ambiente, possibilitando assim o desenvolvimento do senso científico, com a aquisição de estratégias para minimização dos efeitos do lixo em nossas vidas e no ambiente e assim mudar 
atitudes e comportamentos a partir da compreensão, sensibilização e pelo desejo de cumprir o compromisso e responsabilidade com a própria vida, a do outro e ao Meio Ambiente.

Conclui-se em relação à compreensão e envolvimento dos estudantes quanto ás questões da Educação Ambiental, que se deu um grande passo, considerando desde já que os conhecimentos prévios ou adquiridos anteriormente foram reafirmados ou desenvolvidos permitindo o entendimento de novas concepções sobre os problemas ambientais com a aplicação da Sequência Didática "Pegada Ecológica do Lixo".

Percebeu-se que por mais que pareça um assunto muito debatido ainda existem lacunas, visto que vários conteúdos abordados dentro da temática planteada pela "Pegada Ecológica do Lixo" eram desconhecidos pelos alunos. Assim com uma percepção mais totalizadora, a Educação Ambiental, buscou através da sensibilização a partir da temática do lixo, informar e estimular a percepção dos estudantes, de modo a sensibilizá-los para participar de ações que num exercício pleno de cidadania, possam encontrar soluções sustentáveis que assegurem a manutenção e elevação da qualidade de vida.

A partir da compreensão da relação, participação e envolvimento dos estudantes quanto às questões da Educação Ambiental pela Pegada Ecológica do Lixo, tem-se a identificação de elementos que evidenciam o desenvolvimento do senso crítico, analítico e cientifico dos estudantes participantes do 60 anos do Ensino Fundamental.

Destaca-se no senso crítico observados nos estudantes a consciência pragmática ficou ressaltado que estes deveriam evitar cometer os mesmos erros no descaso ao meio ambiente. Quanto ao senso analítico se destaca a compreensão sobre suas decisões de consumo e a geração de novas opções trazendo a responsabilidade do cuidado ambiental e da não geração de resíduos. Finalizando, o senso científico, o que poderia aparecer também como componente crítico e analítico, foi percebido especialmente relacionado ao levantamento de hipóteses, explicação, previsão, justificativa, baseados no conhecimento cientifico adquirido durante a aplicação da Sequência Didática no Recurso Educacional Aberto sobre a Pegada Ecológica do Lixo.

Espera-se com esta pesquisa contribuir com a construção de novos olhares e novas relações, sociais e ambientalmente sustentáveis e ainda garantir o acesso à informação em linguagem adequada, contribuindo para o desenvolvimento de uma consciência crítica e estimulando o enfrentamento das questões ambientais e sociais. 


\title{
CRITICAL, ANALYTICAL AND SCIENTIFIC SENSE OF STUDENTS OF THE 6TH GRADE OF ELEMENTARY SCHOOL IN A DIDACTIC SEQUENCE ON THE GARBAGE ECOLOGICAL FOOTPRINT
}

\begin{abstract}
Education Environmental Education as a cross-cutting theme in the Science Teaching curriculum enables reflections and discussions so that this knowledge contributes to a new stance with actions in its relationship with the environment. This research aimed to analyze the evidence of the development of critical, analytical and scientific sense of students with the application of a Didactic Sequence on the Garbage Ecological Footprint. It could be concluded that the inclusion of Environmental Education in the school curriculum in a contextualized way can give a new meaning to the teaching method and break with isolated and isolated practices and with mechanistic and conservative Education, since the development of integrated and participative actions enhances the discussions that emerge from the relationships between man, society and nature. In addition, the process of raising students' awareness of the problems related to trash issues contributes to becoming critical, analytical and scientifically literate citizens, being active in preserving the environment.
\end{abstract}

KEYWORDS: Garbage ecological footprint. Environmental education. Science teaching. 


\section{REFERÊNCIAS}

AMARAL, R. M. Desenvolvimento e aplicação de um método para o mapeamento de competências em inteligência competitiva. 2006. 209 f. Dissertação (Mestrado em Engenharia de Produção) - Universidade Federal de São Carlos, São Carlos, 2006. Disponível em: http://bdtd.ufscar.br. Acesso em: 10 jan. 2019.

AMARAL, I. M. do. Educação ambiental e ensino de ciências: uma história de controvérsias. Proposições. Revista quadrimestral Faculdade de Educação UNICAMP. Campinas, SP, v. 12, n.1 (34), p. 73 - 93, mar. 2001.

BADARÓ, C. E. Epistemologia e ciência: reflexão e prática na sala-de-aula. Bauru: EDUSC, 2005, p.21-85.

BARDIN, L. Análise de conteúdo. São Paulo: Edições 70, 279 p. 2011.

BRASIL. Lei n 9.795, de 27 de abril de 1999. Dispõe sobre a Educação Ambiental, institui a Política da Educação Ambiental e dá outras providências. Diário Oficial da União, Brasília, 28 abr. 1999. Disponível em: http://www.planalto.gov.br/ccivil 03/leis/19795.htm. Acesso em: 17 de jan. de 2019.

BRASIL. Secretaria de Educação Fundamental. Parâmetros Curriculares Nacionais: terceiro e quarto ciclos do ensino fundamental: língua portuguesa. Brasília: MEC/SEF, 1998.

BAPTISTA, M. A. O. Formação e desenvolvimento do senso crítico no ensino superior: perspectivas em um curso de licenciatura em pedagogia. 2009. $191 \mathrm{f}$. Dissertação (Mestrado em Ciências Humanas) - Universidade do Oeste Paulista, Presidente Prudente, 2009.

BAYARDO, M. G. M. Desde cuándo y desde donde pensar la fomación para la investigación. Educación y Ciencia. 2003. Disponível em: http://educacionyciencia.org/index.php/educacionyciencia/article/view/205/pdf. Acesso em: 17 jan. 2019.

CARRAHER, D. W. Senso crítico: do dia-a-dia às ciências humanas. 9 ed. São Paulo: Pioneira, 2011.

CARVALHO, I. Educação ambiental crítica: nomes e endereçamentos da educação. In: MMA/ Secretaria Executiva/ Diretoria de Educação Ambiental (Org.). Identidades da educação ambiental brasileira. Brasília: MMA, 2004. 
CHASSOT, A. Catalisando transformações na educação. ljuí: Editora Unijuí, 1993.

DELIZOICOV, D. Ensino de Ciências: fundamentos e métodos. 2 ed. São Paulo: Cortez, 2009.

DEL-CORSO, T. M. Indicadores de Alfabetização Científica, Argumentos e Explicações: análise de relatórios no contexto de uma sequência de ensino investigativo. (Mestrado). Faculdade de Educação, Instituto de Física, Instituto de Química e Instituto de Biociências, Universidade de São Paulo, São Paulo. 2014.

DEWEY, J. Democracia e educação. São Paulo: Nacional, 1959.

ESTEBAN, M. P. S. Pesquisa qualitativa em educação: fundamentos e tradições. Porto Alegre: Artmed. 2010.

FREITAS, L.; MORIN, E.; NICOLESCU, B. Carta de transdisciplinaridade. In: NICOLESCU, B. et al. Educação e transdisciplinaridade. Brasília: UNESCO, p. 17781, 2000.

GUIMARÃES, L. R. Atividades para Aulas de Ciências. 1 ed. São Paulo: Nova Espiral, 2009.

GUISASOLA, J. FURIÓ, C. \& CEREBIO, M. Science education based on developing guided research. In: M. V. Thomas, Science Education in Focus, p. 56-83. New Yowk, NY: Nova, 2006.

LOUREIRO, C. F. B. Trajetória e fundamentos da educação ambiental. 2 ed. São Paulo: Cortez, 2006.

LORENZETTI, L.; DELIZOICOV, D. AC no contexto das séries inicias. Ensaio Pesquisa em Educação em Ciências, v. 3, n. 1, p. 1-17, 2001.

MARQUES, R; XAVIER, C. R. Análise da alfabetização científica de estudantes numa sequência didática de educação ambiental no ensino de ciências. Braz. J. of Develop., Curitiba, v. 5, n. 4, p. 2595-2612, apr. 2019a.

MARQUES, R.; XAVIER, C. R. O desenvolvimento do senso analítico no processo de ensino e aprendizagem na Educação Ambiental. RELACult - Revista LatinoAmericana de Estudos em Cultura e Sociedade, v. 5, n. 2, set. 2019b. 
MARQUES, R.; XAVIER, C. R. Análise do Senso Crítico em uma Sequência Didática na Educação Ambiental. REMEA - Revista Eletrônica do Mestrado em Educação Ambiental, v. 35, n.1, 132-150, abr. 2018a. Disponível em:

<https://doi.org/10.14295/remea.v35i1.7430> Acesso em: 13 jul. 2020.

MARQUES, R. Pegada ecológica do lixo: desenvolvimento crítico, analítico e científico na educação ambiental de estudantes do 60 ano do ensino fundamental. 2018. 146 f. Dissertação (Mestrado em Formação Científica, Educacional e Tecnológica) -Universidade Tecnológica Federal do Paraná, Curitiba, 2018b. Disponível em:

<http://repositorio.utfpr.edu.br/jspui/handle/1/2964>. Acesso em: 21 jul. 2020.

MARQUES, R.; XAVIER, C. R. Pegada ecológica do lixo: desenvolvimento e aplicação de uma sequência didática para a Educação Ambiental. Ambiente \& Educação, v. 23, n.2, p. 122-137, 2018.

MORTIMER, E.F; SANTOS, W.L.P. Tomada de Decisão para Ação Social Responsável no Ensino de Ciências. Revista Ciência \& Educação, v. 7, n. 1, p. 95111, 2001.

PEDROSO, C. V. Jogos didáticos no ensino de biologia: uma proposta metodológica baseada em modelo didático. 2009. In Anais do IX Congresso Nacional de Educação - Educere; III Encontro Sul Brasileiro de Psicopedagogia PR (p. 3182-3190). Curitiba, PR. Disponível em:

http://pt.calameo.com/read/0051600938835ab1c48ec. Acesso em: 16 jan. 2019.

PIZARRO, M. V.; LOPEZ JÚNIOR, J. Indicadores de Alfabetização Científica: uma revisão bibliográfica sobre as diferentes habilidades que podem ser promovidas no ensino de Ciências nos anos iniciais. Investigações em Ensino de Ciências, v. 20, n. 1, p. 208-238. 2015. Disponível em:

https://www.if.ufrgs.br/cref/ojs/index.php/ienci/article/view/66/42. Acesso em: 15 jan. 2019.

SASSERON, L. H.; CARVALHO, A. M. P. Almejando a Alfabetização Científica no Ensino Fundamental: a proposição e a procura de indicadores do processo. Investigações em Ensino de Ciências. Porto Alegre, v. 13, n. 3, p. 333-352. 2008.

SAUVÉ, L. Educação Ambiental: possibilidades e limitações. Educação e Pesquisa, v. 31, n. 2, p. 317-322, 2005.

SMITHENRY, D. Integrating guided inquiry into a tradicional chemistry curricular framework. International Journal of Science Education, 32(13), 1689-1714. 2010. 
VIGOTSKY, L. Pensamento e linguagem. 3 ed. São Paulo: M. Fontes. 1991.

ZOLLER, U. Expanding the meaning of STS and the movement across the globe. In: YAGER, R. E. (Ed.). The science, technology, society movement. Washington, DC: National Science Teachers Association, p. 125-134, 1993.

ZOLLER, U. Are lecture and learning: are they compatible? maybe for LOCS; unlikely for HOCS, Journal of Chemical Education, v. 70, n. 3, p. 195-197, 1993.

Recebido: 19 jan. 2019

Aprovado: 20 mai. 2020.

DOI: $10.3895 /$ rbect.v13n2.9374

Como citar: MARQUES, R.; XAVIER, C. R. Senso crítico, analítico e científico de estudantes do 6o ano do ensino fundamental numa sequência didática sobre a pegada ecológica do lixo. Revista Brasileira de Ensino de Ciência e Tecnologia, Ponta Grossa, v.13, n. 2, p. 345-371, mai./ago. 2020. Disponível em: $<$ https://periodicos.utfpr.edu.br/rbect/article/view/9374>. Acesso em: XXX.

Correspondência: Ronualdo Marques - ronualdo.marques@gmail.com

Direito autoral: Este artigo está licenciado sob os termos da Licença Creative Commons-Atribuição 4.0 Internacional. 